\title{
¿UN CUENTO ANTIRROMÁNTICO DE JUAN EUGENIO HARTZENBUSCH?
}

\author{
Rocío CHARQues GÁMEZ \\ Universidad de Alicante
}

¿Critica, en algún momento de su carrera literaria, Juan Eugenio Hartzenbusch el Romanticismo? Si es así, ¿a qué aspecto o aspectos de éste se está refiriendo? Recordemos que no era algo extraordinario que los propios escritores románticos satirizaran al citado movimiento literario. Los escritores costumbristas e incluso los mismos dramaturgos incluían en sus obras notas cómicas con esta finalidad (Caldera 2002)'. Pero conviene determinar el objeto de estas críticas. El Romanticismo, asimilado por la gente común, se convirtió en una moda y, por tanto, se modificó su significado primigenio. La juventud -como ocurre en todas las épocas- fue la que primero se apuntó al nuevo sentir y adquirió una nueva visión del mundo, aunque deformada respecto al ideario original del Romanticismo. A partir de este momento, las caricaturas del hombre romántico se suceden como, por ejemplo, a través de la prensa. En este círculo entran en juego autores románticos como el famoso autor de Los amantes de Teruel. Pero, ¿Hartzenbusch realmente es un escritor romántico? Allison Peers opina que «pese a todos sus entusiasmos juveniles, era temperamentalmente un sobrio estudioso, mucho más inclinado al ideal de moderación que al del predominio de la imaginación o de la pasión desenfrenada» (Peers 1973, pág. 160). Es en su edad madura

${ }^{1}$ Ermanno Caldera recoge algunas muestras de estas críticas de viñetas, cuentos y, sobre todo, piezas teatrales de Manuel Bravo, Manuel Bretón de los Herreros y Antonio Iza Zamacola. Lo que buscaban estos teóricos era encontrar un punto medio entre las exageraciones tanto de los románticos como de los clasicistas. 
cuando escribe el cuento Historia de dos bofetones (Hartzenbusch 1863a, págs. 41-44; Hartzenbusch 1863b, págs. 49-51)2. Este relato aparece en la revista alicantina Álbum literario, en 1863. Tanto personal como profesionalmente, nuestro escritor se encuentra en un periodo de madurez. El cuento constituye un ejemplo de crítica de una moda histórica a través de un texto de creación literaria. El famoso dramaturgo no duda en censurar a quienes han malinterpretado el concepto de romántico.

El relato se publica en dos partes en la revista citada. La primera parte transcurre durante la Pascua de Pentecostés de 1689; mientras que la segunda se sitúa en el año 1839. Ambas historias tienen lugar en Madrid y presentan un juego de contrastes, con el que el narrador pretende demostrar, en clave irónica, las consecuencias que ejerce sobre una joven el bofetón propinado por el familiar más cercano, en ambos casos una mujer (la madre o la tía). Tres características podemos resaltar de este cuento: los elementos costumbristas ${ }^{3}$, la nota de crítica e ironía, así como la moraleja. En la primera parte, la acción se desenvuelve por la mañana en un recorrido espacial reducido y centrado en el convento de San Jerónimo. Hartzenbusch no deja de lado el interés por el sabor local y añade algunas notas de tipo costumbrista a la narración. Así, describe cómo se divertía la gente de entonces en el Prado. Las dos partes se abren y cierran con elementos contrapuestos. La acción de la primera comienza por la mañana, mientras que la segunda (como era de esperar al tratarse de la época romántica) lo hace de madrugada. El bofetón se propina en el medio de cada una de las historias y en los dos casos provoca un cambio en la vida de la protagonista. Pero la consecuencia de la bofetada desenlaza felizmente la primera parte, mientras que acaba en drama en la segunda. El narrador no está de acuerdo con ninguna de las dos formas de entender el mundo, pero parece preferir la antigua porque al menos podía controlar las pasiones juveniles. El relato se cierra con una máxima: «A otros caracteres, otro

${ }^{2}$ Mariano Baquero Goyanes, que incluye a Juan Eugenio Hartzenbusch entre los cuentistas post-románticos, nos resume en las siguientes líneas la trayectoria cuentística de nuestro autor: «Por los años románticos o inmediatamente post-románticos inicia su labor como cuentista Juan Eugenio Hartzenbusch (1806-1880). Hacia 1845 empezaron a aparecer en entregas de 16 páginas, con grabados, Las mil y una noches españolas, colección de cuentos y leyendas de Hartzenbusch, Romero Larrañaga, Huici, Andueza, Rubi, etc. Después Hartzenbusch colabora con el Semanario Pintoresco Español con relatos que se publican en $\operatorname{los}$ años $1848,1849,1850,1851$ y siguientes. En 1861 aparece una colección de Cuentos y fäbulas de este autor reeditada en 1862. Después, la Revista de España (...) también publica alguna narración suya en 1869» (Baquero Goyanes 1992, pág. 53).

${ }^{3}$ Los elementos costumbristas que hemos localizado en nuestro texto son el juego con los nombres de los personajes (pensemos en el vicjo alegre de Mesonero Romanos «Don Plácido Cascabelillor), la descripción de costumbres sociales, la aparición de personajes típicos. Sobre los rasgos de la literatura costumbrista se puede consultar el artículo de Pilar Palomo, Alejandro Pérez Vidal y Enrique Rubio Cremades, recogido en la bibliografia. Sobre la relación entre el cuadro de costumbres y el cuento finisecular véase Ezama Gil 1992, págs. 59-62. 
modo de manejarlos; otros tiempos, otras costumbres) (Hartzenbusch 1863b, p. 51). El hecho de llevar una moraleja lo asemeja a la fábula que, como sabemos, Hartzenbusch cultiva. Entre las fábulas escritas por nuestro autor (recogidas en edición definitiva en 1888), hay algunas que tratan el tema de la educación. Por ejemplo, la desobediencia del joven -normalmente una chica- conduce a su perdición, como en las fábulas «El ratoncillo y el gato» (Hartzenbusch [1888] 1973, págs. 132-134) , y «La hija de Seyano» (Ibid., págs. 139-141)5. En otras se señala que la juventud inexperta necesita un guía para aprender el buen camino, como en «E1 látigo» (Ibíd., pág. 31) ${ }^{6}$, y «Pedro Enreda» (Ibíd., págs. 20-21)?

El espacio en el que tienen lugar las historias es Madrid, pero el Madrid de dos épocas diferentes: la de fines del XVII y la de comienzos del XIX. Los personajes llevan nombres significativos. Las protagonistas de 1689 son la joven doña Gabriela y su madre, doña Lupercia. Los personajes masculinos son el muchacho del que está enamorada la protagonista, Gonzalo (Gonzalvico para la madre) y el pretendiente de ella, don Canuto de la Esparraguera. Es evidente el uso de nombres masculinos cómicos. En cuanto a los protagonistas de la segunda historia tenemos a la joven doña Dolorcitas del Tornasol -prototipo de mujer romántica- y su tía doña Gregoria. La primera parte del cuento empieza en 1689. El primer personaje que aparece es un mendigo «tan andrajoso como lucio y colorado, con un ojo y un pie no más, dos jorobas, no menos, un par de muletas, muchos remiendos en la ropa, e infinitas marrullerías de trapos adentro» (Hartzenbusch 1863a, pág. 41). Este mendigo, entre otras actividades, se dedica a enviar en secreto misivas entre enamorados. Las protagonistas del relato son dos mujeres (una madre y una hija). La descripción de las mismas antecede al conocimiento de sus nombres. La voz de cada una de ellas nos dan las claves para averiguar su carácter: unas son «humildes como de quien pide silencio» (Ibid., pág. 42) y, por tanto, de una persona a la que no le gusta el escándalo ni las habladurías, y otras son «imperiosas como de quien manda obediencia» (Ibíd., pág. 42). Después de las voces se describe el atavío de las damas, que no delata la clase social a la que pertenecen. Un manto las cubre y llevan un hábito del Carmen. Es el rosario el que marca la diferencia pues está «labrado de filigrana de oro, con medallas preciosas y una cruz sembra-

${ }^{4}$ La fábula cuenta cómo el ratoncillo acaba devorado por un gato al no seguir el consejo de su madre. La moraleja reza así: «La juventud sin experiencia/ corre en el mundo suerte igual» (pág. 134).

5 "La hija de Seyano» sigue el mismo esquema, pero los personajes son humanos.

'La moraleja de esta fábula se puede aplicar, como las otras, al final de doña Dolorcitas del Tornasol. Dice así: «Siempre verás que el vicio/ se labra por sus manos el suplicio» (pág. 31).

7 Esta fábula advierte a los padres que si no enseñan a sus hijos desde pequeños a comportarse, de mayores continuarán por mal camino: «Malas inclinaciones de muchachos, /que el rigor a su tiempo no endereza./ darán el fruto de partir a cachos/al indolente padre la cabeza» (pág. 21). 
da de diamantes» (Ibíd., pág. 42). La segunda vez en la que el narrador se fija en la voz de la madre usa los calificativos «grave y no muy recatada» (Ibid., pág. 42) y Gabriela, la hija, contesta con voz «sumisa y apagada» (Ibid., pág. 42). Gonzalo, el enamorado de Gabriela, es un «caballero muy atildado de bigotes, pero algo raído de ropilla» (Ibíd., pág. 42) ${ }^{8}$. Otros personajes que dan color al cuento son los sirvientes, los curas y los monaguillos, aparte de las personas que pasean por el Prado el domingo de Pascua: los jóvenes que van a ver a las muchachas, los mendigos, los vendedores ambulantes, etc. Los tipos citados, a continuación, son los usuales en los relatos costumbristas, personajes populares como las

naranjeras despilfarradas, bolleros sucios, alojeros montañeses, harto más a propósito para terciar la pica que para portear la garrafa, demandantes para monjas, para frailes, para hospitales, para presos, para una necesidad, para una dote, para mandar pintar un exvoto, para comprar un cilicio, todos se apiñaban a las puertas del convento, y estimulados los unos por su interés, los otros por su celo caritativo, disputaban sobre el puesto, lo defendían o lo usurpaban tal vez a cachetes (Ibid., pág. 42).

Asimismo, los personajes que rodean a las damas a la salida de la misa para pedirles limosna proporcionan sabor local al relato. La clase alta está representada por los amigos y conocidos de doña Lupercia y su hija. El elemento que sirve para diferenciarlos es el grupo de lacayos que se encuentra a poca distancia de ellos. La conversación de estos personajes gira en torno a las novedades teatrales, la moda y la política. El futuro esposo de Gabriela aparece a los ojos de la chica como un ser inculto y feo, a pesar de tener riquezas y ser honrado y discreto. La incultura la pone de manifiesto al comentar Gabriela que él no sabe ni escribir una redondilla y, además, el narrador le pone el ridículo nombre de don Canuto de la Esparraguera 9 .

Por otro lado, la segunda historia la abre un sereno del Madrid de 1839. Los avances que ha sufrido la ciudad vienen representados por ese personaje, que tiene un farol numerado pendiendo de un chuzo. La siguiente protagonista es descrita antes de que conozcamos su nombre con rasgos típicos del personaje romántico, pero con el guiño irónico cómplice del narrador, que recalca los elementos tópicos: ella es «una interesante joven de negros ojos y negra cabellera, el rodete en la nuca y los rizos hasta el seno, se deshacía al amor de la lumbre en amargo llanto que inundaba sus mejillas, medianamente flacas y descoloridas» (Hartzenbusch 1863b, pág. 49). La joven se llama doña Dolorcitas del Tornasol -fijémonos en que la protagonista exagera sus sentimientos y termina sufriendo y suicidándose, y en la musicalidad de Tornasol-. Ella vive con su anciana tía doña Gregoria. El

${ }^{8}$ La presentación de los personajes nos recuerda a las acotaciones teatrales.

${ }^{\circ}$ Recuérdese la frase: No saber hacer la $O$ con un canuto. 
vecindario está formado, entre otros, por milicianos nacionales. Con ironía, el narrador nos cuenta que entre los vecinos hay una coja chismosa a la que no le da tiempo a coger su muleta pero, en cambio, sí que puede ponerse las gafas para asomarse y enterarse del escándalo provocado por doña Dolorcitas. Otro vecino, engañado, va a avisar a los bomberos, celadores, alcaldes, serenos y milicianos del revuelo en el edificio. En este momento, todo este colectivo es criticado por el narrador, porque solo cuando destrozan cuanto encuentran a su paso y descubren que no ha ocurrido nada extraordinario, vuelven a sus puestos con la conciencia tranquila y pensando que han hecho bien su trabajo. Por otra parte, el vigésimo séptimo amante de Dolorcitas no es su hombre ideal, pero se enamora de él por librarse de su tía y porque le encuentra ciertas trazas novelescas.

Los lugares de ambas historias así como los personajes, suelen presentarse en contraposición con épocas pasadas o futuras. En el primer relato se cita la iglesia de San Sebastián; la calle de las Huertas, que es «harto desigual y barrancosa entonces» (Hartzenbusch 1863a, pág. 41); el Prado; la lonja de San Sebastián; la casa de las protagonistas cerca del Prado. A la iglesia de San Jerónimo acuden las multitudes, no como en el XIX -apunta el narrador-. En esa época la gente pasea por el Prado para vender y reunirse con otras personas, entre otras cosas. En el segundo relato no estamos en una iglesia sino en el gabinete en el que lee la joven, que está lleno de estampas de personajes románticos como el Corsario, Bug-Jargal, Ivanhoe o Atala. En lugar de ir a misa, la muchacha acude a academias de baile, donde un muchacho le da «un billete color de rosa, perfumado y con orla y sello y canto dorado, primera entrega del vigésimo séptimo galán, hecha fortuitamente aquella noche» (Hartzenbusch 1863b, pág. 49). Aparte de la calle en la que está el sereno y la casa de doña Gregoria, se nombran en esta parte un hospicio para mujeres, la feria de Jadraque, un figón de la calle Fuencarral y el canal del Manzanares.

La nota sobresaliente de 1689 es la religiosidad y en 1839, el mal entendido romanticismo. La religión lo impregna todo en el primer relato y, por ello, el narrador elige un domingo de Pascua para desarrollar la acción. Con ironía, se fija en la absurda inscripción en latín del dintel de la puerta de entrada de la casa de la protagonista: «RESUR REX IT TERTIA DIE AN. 16 MAR. IHS. IPH. 88» (Hartzenbusch 1863a, pág. 41), que el narrador traduce por «Resucitó al tercero día, año mil seiscientos, María, Jesús, José, ochenta y ocho» (Ibíd., pág. 4l). Por otro lado, se va haciendo referencia, a lo largo del cuento, al tipo de literatura que gusta entonces son los sonetos («en veinte sonetos encarezca la grana de tus mejillas») (Ibid., pág. 42) ${ }^{10} \mathrm{y}$ las redondillas (que no sabe escribir el futuro marido

10) Uno de los tópicos de la lírica barroca es el juego que contrasta el rojo (que representa la pasión) y el blanco (como símbolo de la frialdad), que se sucede en las descripciones que el poeta hace 
de Gabriela). Era común en aquella época la venta callejera de poemas. Un ciego quiere vender un romance de un ajusticiado, otro una jácara a lo divino y hay quien intenta lo mismo con una historia de amor del conde de Saldaña. En el XIX, vemos que Dolorcitas disfruta con lecturas románticas, en las que el héroe siempre está «oprimido por imaginarios males por gusto del autor» (Hartzenbusch 1863b, pág. 49). Las lecturas de Gregoria son otras y, cuando su madre la castiga, la encierra con las capitulaciones matrimoniales y un tratado agrícola en el que el autor da consejo a las mujeres de cómo actuar ante situaciones en la que corre peligro su virtud, o de cómo salir virtuosamente arregladas a la calle. Por su parte, Dolorcitas ha tenido veintiséis amantes y los ha rechazado a todos menos al que hace el número veintisiete por tener, para ella, algún rasgo novelesco. La crítica del narrador de este tipo de lecturas continúa porque dice que la protagonista lee «mentirosas páginas» (Ibíd., pág. 50). Cuando Dolorcitas le pone excusas a su tía por el escándalo que provoca usa la «peregrina fraseología moderna» (Ibíd., pág. 50) acompañándose de suspiros y lágrimas. Sobre las mejillas «alfeñicadas y macilentas» (Ibíd., pág. 50) de su sobrina, doña Gregoria propina un bofetón. Tras esto, doña Dolorcitas pierde el control y comienza a pegar a su tía (obsérvese la diferente reacción entre las protagonistas de las dos partes). A partir de aquí, la cadena de sucesos fatales y folletinescos se va sucediendo (huida y robo, representaciones teatrales por los pueblos sin éxito, cárcel y hospicio) hasta que culmina con la muerte de la romántica sobrina (suicidio en el Manzanares). Este trágico fin contrasta con el de Gabriela, que, tras rechazar la oferta romántica de Gonzalo de huir a pesar de que él no tiene nada que ofrecerle, acaba felizmente casada con don Canuto de la Esparraguera y convertida en una rica y oronda matrona.

Las notas irónicas aparecen repartidas en ambas partes, pero son más abundantes en la segunda, por tanto critica más el modo de ser actual, el romántico, que el de los clásicos. El tono moralizante que tiene el texto (evidente en la moraleja final) puede disgustar al lector de hoy, pero los personajes que van asomando por sus páginas aportan colorido a la narración y nos aproximan a la vida cotidiana de diferentes épocas gracias al estilo vivaz que toma de los costumbristas. Como dijo Juan Valera en una de sus críticas, los «cuentos, o populares o de invención, del señor Hartzenbusch están narrados con una gracia y una naturalidad admirables, y no destruye la candidez y la frescura del estilo la intención moral o filosófica que

de la dama de la que dice estar enamorado. Este soneto que propone doña Lupercia no sería extraño, pues recordemos que algunos poemas escritos entonces llevaban títulos como «A una dama que tenía los ojos enfermos», de Lope de Vega; o los de Francisco de Quevedo, «A Aminta, que teniendo un clavel en la boca, por morderle, se mordió los labios y salió sangre» y «A Aminta, que para enseñar el color de su cabello llegó una vela y se quemó un rizo que estaba junto al cuello». Sobre los tópicos de la lírica barroca puede consultarse la antología Tiempo y caída, de Ramón Andrés (Andrés 1994). 
en cada uno de ellos sabe el autor ocultar discretamente) (Valera 1961, pág. 208); aunque en este caso la moraleja es explícita. 


\section{BIBLIOGRAFÍA}

ANDRÉS, Ramón, 1994. Tiempo y caída, Barcelona, Quaderns Crema, 2 vols.

BAQuero GoYAneS, Mariano, 1992. El cuento español: Del Romanticismo al Realismo, Madrid, CSIC.

CALderA, Ermanno, 2002. «Los románticos se burlan de sí mismos. Algunos apuntes sobre el Romanticismo existencial», en Romanticismo 8. Los románticos teorizan sobre si mismos, Bologna, Il Capitello del Sole, págs. 63-76.

EZAMA GIL, Ángeles, 1992. El cuento de la prensa y otros cuentos. Aproximación al estudio del relato breve entre 1890 y 1900, Universidad de Zaragoza.

HARTZENBUSCH, Juan Eugenio, 1863 a. «Historia de dos bofetones. 1689-1839. Primera parte». Álbum literario, Alicante, número 6, págs. 41-44.

- 1863 b. «Historia de dos bofetones. Conclusión. 1689-1839. Segunda parte». Album literario, Alicante, número 7, págs. 41-44.

- [1888] 1973. Fábulas, ed. Ricardo NAVAs Ruiz, Madrid, Espasa-Calpe.

PAlomo, Pilar, Alejandro PÉREZ VIDAL y Enrique RUbIo CremADES, 1997. «La literatura costumbrista» en Guillermo CARNERO (dir.), Historia de la literatura española. Siglo XIX, Madrid, Espasa Calpe, págs. 151-234.

PEERS, E. Allison, 1973. Historia del movimiento romántico español, Madrid, Gredos, 2 tomos.

VAlerA, Juan, 1961. «Cuentos y fábulas, de Juan Eugenio Hartzenbush (Tomos l y II)», en Obras completas, estudio preliminar de Luis Araujo Costa, Madrid, Aguilar, tomo II, págs. 207-210. 